\title{
Anti-programmed death ligand 1 (PD-L1) inhibitors in metastatic gastric cancer
}

\section{Jang Ho Cho, Jeeyun Lee}

Division of Hematology-Oncology, Department of Medicine, Samsung Medical Center, Sungkyunkwan University School of Medicine, Seoul, Korea

Received: August 25, 2017

Revised: October 15, 2017

Accepted: October 19, 2017

Corresponding author:

Jeeyun Lee

Division of Hematology-

Oncology, Department of

Medicine, Samsung Medical

Center, Sungkyunkwan

University School of Medicine, 81 Irwon-ro, Gangnam-gu,

Seoul 06351, Korea

Tel: +82-2-3410-3459

E-mail: jyunlee@skku.edu

\section{ABSTRACT}

Metastatic gastric cancer (GC) with limited therapeutic options has a poor prognosis, and therefore, major therapeutic advances are needed. Comprehensive genomic characterization has improved understanding of GC but a great majority of genomic profiling has not been effectively translated to the clinical benefit yet. The introduction of immunotherapy with anti-programmed death ligand 1 (PD-L1) antibody such as pembrolizumab or nivolumab resulted in a rapid paradigm shift in the field of medical oncology and their clinical indication has been expanding in the past few years. Now, the era of immunotherapy in metastatic GC has arrived with recent trial results in survival benefit from anti-PD-L1 antibody. Herein, we review the mechanisms of immunotherapy, clinical trials that have been conducted or are in progress, and the potential for PD-L1 as a predictive biomarker for GC.

Keywords: Gastric; Immune checkpoint; Neoplasms; Programmed cell death protein 1; Programmed death ligand 1
This is an Open Access article distributed under the terms of the Creative Commons Attribution Non-Commercial License (http:// creativecommons.org/licenses/ by-nc/4.0/).

\section{INTRODUCTION}

Gastric cancer (GC) is the second leading cause of cancer-related mortality worldwide, with an estimated 723,000 deaths in 2012 [1,2]. Several immune checkpoint inhibitors that block the key immune checkpoints, such as cytotoxic T-lymphocyte antigen 4 (CTLA-4), programmed cell death protein 1 (PD-1), and/or programmed death ligand 1 (PD-L1), had been approved by the U.S. Food and Drug Administration (FDA) in several cancer types including melanoma, bladder, and lung cancer. We extensively reviewed the current ongoing clinical research effort and translational research for $\mathrm{GC}$ regarding immune checkpoint inhibitors.

\section{IMMUNE CHECKPOINT INHIBITORS IN GC}

Two anti-PD-L1 inhibitors, pembrolizumab and nivolumab, were approved by the U.S. FDA for the treatment of metastatic melanoma in 2014 [3,4]. Subsequently, immune checkpoint inhibitors have been approved by the U.S. FDA for lung cancer, renal cell carcinoma (RCC), Hodgkin's 
Table 1. Select clinical trials of immune checkpoint inhibitors for metastatic gastric cancer

\begin{tabular}{|c|c|c|c|c|c|c|}
\hline $\begin{array}{l}\text { Study } \\
\text { (ClinicalTrials. } \\
\text { gov identifier) }\end{array}$ & Phase & No. & Setting & Treatment & $\begin{array}{l}\text { Results (primary } \\
\text { end-point) }\end{array}$ & Ref \\
\hline $\begin{array}{l}\text { Ipilimumab } \\
\text { CA184-162 } \\
\text { (NCT01585987) }\end{array}$ & II & 114 & $\begin{array}{l}\text { Maintenance after } \\
\text { first-line }\end{array}$ & $\begin{array}{l}\text { Ipilimumab vs. best supportive care after } \\
\text { response or stability to platinum and } \\
\text { fluoropyrimidine doublet }\end{array}$ & $\begin{array}{l}\text { Negative } \\
2.9 \text { months vs. } 4.9 \\
\text { months (irPFS) }\end{array}$ & {$[14]$} \\
\hline Tremelimumab & II & 18 & Second-line & Tremelimumab $15 \mathrm{mg} / \mathrm{kg}$ every 90 day & $\begin{array}{l}1 \text { partial response } \\
\text { (ORR) }\end{array}$ & {$[15$} \\
\hline $\begin{array}{l}\text { KEYNOTE-012 } \\
\text { (NCT01848834) }\end{array}$ & $\mathrm{lb}$ & 36 & First-line & Pembrolizumab $10 \mathrm{mg} / \mathrm{kg}$ once every 2 weeks & $\begin{array}{l}\text { 22\% (ORR) in PD- } \\
\text { L1 positive gastric } \\
\text { cancer }\end{array}$ & {$[11]$} \\
\hline $\begin{array}{l}\text { KEYNOTE-059 } \\
\text { (NCT02335411) }\end{array}$ & II & 133 & Third-line & Pembrolizumab 200 mg Q3W & $16.4 \%$ (ORR) & {$[16$} \\
\hline $\begin{array}{l}\text { CheckMate-032 } \\
\text { (NCT01928394) }\end{array}$ & $1 / I I$ & 160 & Second-line or later & $\begin{array}{l}\text { Nivolumab } 3 \text { mg/kg Q2W (N3), nivo } 1 \text { mg/kg+ } \\
\text { ipilimumab } 3 \text { mg/kg (N1+|3), or nivolumab } 3 \\
\text { mg/kg+ipilimumab } 1 \text { mg/kg (N3+l1) Q3W×4 } \\
\text { cycles, followed by nivolumab } 3 \text { mg/kg Q2W }\end{array}$ & $\begin{array}{l}16 \%(\mathrm{ORR}): 14 \% \\
\text { (N3) } 26 \%(\mathrm{~N} 1+\mathrm{I} 3) \\
\text { and } 10 \%(\mathrm{~N} 3+\mathrm{I} 1)\end{array}$ & {$[10]$} \\
\hline $\begin{array}{l}\text { ONO-4538-12 } \\
\text { (NCT02267343) }\end{array}$ & III & 493 & Second-line or later & Nivolumab 3 mg/kg vs. placebo & $\begin{array}{l}5.3 \text { months vs. } 4.1 \\
\text { months (OS) }\end{array}$ & {$[12]$} \\
\hline \multirow[t]{2}{*}{$\begin{array}{l}\text { JAVELIN } \\
\text { (NCT01772004) }\end{array}$} & $\mathrm{lb}$ & 89 & $\begin{array}{l}\text { Maintenance after } \\
\text { first-line }\end{array}$ & Avelumab 10 mg/kg Q2W & $\begin{array}{l}\text { 9\% (RR), } 12 \text { weeks } \\
\quad(\mathrm{PFS})\end{array}$ & {$[13$} \\
\hline & & 62 & Second-line & & $\begin{array}{l}10 \%(\mathrm{RR}), 6 \text { weeks } \\
\text { (PFS) }\end{array}$ & \\
\hline
\end{tabular}

IrPFS, immune-related progression-free survival; ORR, objective response rate; PD-L1, programmed cell death protein ligand 1; OS, overall survival; RR, response rate.

disease and head and neck cancer since then. Many studies have reported long-term responses to anti-PD-L1 antibodies with acceptable safety profiles in lung cancer [5], RCC [6], bladder cancer [7], and chemoresistant Hodgkin disease [8]. In addition, solid tumors with high mutational load or microsatellite instability (MSI-high) have shown dramatic response to pembrolizumab in recent trials including colon cancer, GC, endometrial cancer, etc. $[9,10]$. Based on this finding, pembrolizumab has been approved in MSI-high tumors in U.S. Table 1 lists selected clinical trials of immune checkpoint inhibitors for metastatic GC [10-16].

\section{PEMBROLIZUMAB}

The phase lb study KEYNOTE-012 (NCT01848834) evaluated the safety and activity of pembrolizumab in PD-L1 positive $\mathrm{GC}(\mathrm{n}=36)$. The primary endpoints were safety and response rate. The adverse events were manageable, and the response rate was $22 \%$ in PD-L1 positive GC patients who have failed to several lines of chemotherapy, thus very promising. There was no correlation between PD-L1 expression and clinical responses to pembrolizumab in the KEYNOTE-012 trial but further biomarker analysis was not extensively performed due to limited tissue specimens from the cohort [11]. In KEYNOTE-059 (NCT02335411), in GC patients who received 2 prior lines of therapy ( $n=133)$, the objective response rate (ORR) was 16.4\%; for those with PD-L1 positive tumors in the thirdline setting $(n=75)$, the ORR was $22.7 \%$; in patients with PDL1 negative tumors ( $n=58)$, the ORR was $8.6 \%$. Hence, the ORR was higher in patients with PD-L1 positive tumors when compared with PD-L1 negative GC but importantly, responses were observed in patients with PD-L1 negative tumors [16]. Among the several ongoing trials, the KEYNOTE-061 (NCT02370498) is testing pembrolizumab versus paclitaxel after progression following a first-line platinum-based therapy. The KEYNOTE-062 trial (NCT02494583) is comparing pembrolizumab as monotherapy or in combination with platinum and 5-fluorouracil (5-FU) in a first-line setting (Table 2). The two trials are currently ongoing. Currently, a phase II pembrolizumab trial (NCT02589496) which is a single-center trial 


\section{PRECISION AND FUTURE MIEDICINE}

Anti-PD-L1 inhibitors in gastric cancer

Table 2. Ongoing clinical trials of immune checkpoint inhibitors for gastric cancer

\begin{tabular}{|c|c|c|c|}
\hline $\begin{array}{l}\text { Study } \\
\text { (ClinicalTrials.gov identifier) }\end{array}$ & Phase & Intervention & Primary end-points \\
\hline \multicolumn{4}{|l|}{ First-line } \\
\hline ONO-4538-37 (NCT02746796) & $1 / I 1$ & Fluoropyrimidine and platinum with or without nivolumab & PFS and OS \\
\hline NCT02954536 & $\|$ & Pembrolizumab in combination with trastuzumab and chemotherapy & 6-month PFS \\
\hline NCT02901301 & IB/II & Pembrolizumab in combination with trastuzumab, capecitabine, and cisplatin & RP2D; 6-week ORR \\
\hline NCT02864381 & II & GS-5745 plus nivolumab vs. nivolumab alone & 2-year ORR \\
\hline \multicolumn{4}{|l|}{ Maintenance after first-line } \\
\hline \multicolumn{4}{|l|}{ Second-line } \\
\hline KEYNOTE-181 (NCT02564263) & III & Pembrolizumab vs. irinotecan or paclitaxel or docetaxel & PFS and OS \\
\hline KEYNOTE-061 (NCT02370498) & III & Pembrolizumab vs. paclitaxel & $\begin{array}{l}\text { PFS and OS in } \\
\text { PD-L1+tumors }\end{array}$ \\
\hline KEYNOTE-063 (NCT03019588) & III & Pembrolizumab vs. paclitaxel & PFS and OS \\
\hline D4190C00021 (NCT02340975) & $\mathrm{lb} / \mathrm{II}$ & Durvalumab vs. tremelimumab vs. durvalumab and tremelimumab & $\begin{array}{l}\text { Phase Ib: DLT } \\
\text { Phase II: ORR and } \\
\text { 6-month PFS }\end{array}$ \\
\hline NCT02999295 & $1 / I I$ & Nivolumab plus ramucirumab & DLTs and PFS \\
\hline \multicolumn{4}{|l|}{ Third-line } \\
\hline ONO-4538-12 (NCT02267343) & III & Nivolumab vs. placebo & OS \\
\hline $\begin{array}{l}\text { JAVELIN Gastric } 300 \\
\text { (NCT02625623) }\end{array}$ & III & $\begin{array}{l}\text { Avelumab and best supportive care vs. paclitaxel or irinotecan and best } \\
\text { supportive care or best supportive care }\end{array}$ & 2-year OS \\
\hline NCT02935634 & II & Nivolumab and ipilimumab vs. nivolumab and BMS-986016 & ORR, DOR, and PFSR \\
\hline NCT03122548 & $\|$ & CRS-207 in combination with pembrolizumab & Adverse events \\
\hline NCT02589496 & II & $\begin{array}{l}\text { Pembrolizumab as salvage therapy in metastatic GC } \\
\text { (integrated genomic analysis) }\end{array}$ & $\begin{array}{l}\text { ORR, genomic } \\
\text { profiling }\end{array}$ \\
\hline
\end{tabular}

5-FU, 5-fluorouracil; PFS, progression-free survival; OS, overall survival; RP2D, recommended phase II dose; ORR, overall response rate; PD-L1, programmed cell death protein ligand 1; DLT, dose-limiting toxicity; MTD, maximum tolerated dose; MAD, maximum administered dose; RR, response rate; DOR, duration of response; PFSR, progression-free survival rate.

a)Also in third-line study.

at Samsung Medical Center with integration of pre and post-biopsies has been completed patient accrual $(n=60)$. This trial results, hopefully, may shed light into identifying a subset of GC patients who may benefit the most from pembrolizumab. 


\section{NIVOLUMAB}

In contrast to pembrolizumab, nivolumab has been investigated in patients regardless to PD-L1 status (both PD-L1 positive and negative GCs) and responses have been seen in both cohorts. Recently, in a randomized phase III trial ONO-4538 (NCT02267343), nivolumab was evaluated as a monotherapy versus placebo (2:1) in metastatic GC after second or later lines $(n=493)$ [12]. The study reported significant prolongation of overall survival (OS) (5.3 months vs. 4.1 months) and disease-free survival (1.61 months vs. 1.45 months) in nivolumab arm when compared to best supportive care, respectively with statistical significance. This study documented a response rate of $11 \%$ and all comer GC patients were enrolled [12]. Based on this trial, nivolumab is expected to receive authority approval in Japan and Korea in late 2017 or early 2018. The GC cohort of CheckMate 032 [10] enrolled patients on nivolumab alone and two different doses of nivolumab in combination with ipilimumab. ORR was the highest with nivolumab $1 \mathrm{mg} / \mathrm{kg}$ with ipilimumab $3 \mathrm{mg} / \mathrm{kg}$ (26\%, 12 of 46 patients), relative to the nivolumab $3 \mathrm{mg} / \mathrm{kg}$ ( $14 \%, 8$ of 59 patients), or nivolumab $3 \mathrm{mg} / \mathrm{kg}$ with ipilimumab $1 \mathrm{mg} / \mathrm{kg}$ (10\%, 5 of 49 patients) cohorts. In the nivolumab alone arm, response rate was higher in PD-L1-positive GC (27\%) when compared to PD-L1 negative GC (12\%); the highest response rate was observed in the combination arm (nivolumab $1 \mathrm{mg}$ / $\mathrm{kg}$ with ipilimumab $3 \mathrm{mg} / \mathrm{kg}$; 44\% in PD-L1 positive and 21\% in PD-L1 negative cohort) (Table 3). Given these notable find- ings, a phase III trial CheckMate-649 (NCT02872116) is currently ongoing to enroll patients in nivolumab plus ipilimumab versus FOLFOX (oxaliplatin plus 5-fluorouracil) or XELOX (oxaliplatin plus capecitabine) as front-line therapy (Table 2).

\section{DURVALUMAB (MEDI-4736)}

Durvalumab is currently in a phase I study to evaluate its efficacy and safety in GC patients with GC (NCT01693562). Most frequent treatment-related adverse events were fatigue, nausea, and rash. Evidence of clinical activity has been seen across all histologies [17]. More recently, a phase II PLATFORM study (NCT02678182) is ongoing. The aim of this study is to evaluate the efficacy and safety of durvalumab for maintenance therapy in GC.

\section{AVELUMAB}

Another promising immune checkpoint inhibitor is avelumab. A large phase Ib JAVELIN trial $(n=151)$ of first-line avelumab maintenance treatment reported a response rate of $9 \%$ with a median progression-free survival (PFS) of 12 weeks; second-line treatment reported a response rate of $10 \%$ with a median PFS of 6 weeks (NCT01772004) [18]. The adverse events reported were most common infusion reactions and fatigue [13]. Given the promising results of this trial, JAVELIN Gastric 100 (NCT\#02625610) and JAVELIN Gastric 300 (NCT\#02625623) phase III trials are underway (Table 2).

Table 3. Selected clinical trials evaluating PD-L1 as a predictive biomarker

\begin{tabular}{|c|c|c|c|c|c|c|}
\hline $\begin{array}{l}\text { Study } \\
\text { (ClinicalTrials. } \\
\text { gov identifier) }\end{array}$ & Phase & No. & Setting & Treatment & Results according to PD-L1 & Ref \\
\hline \multicolumn{7}{|l|}{ Pembrolizumab } \\
\hline $\begin{array}{l}\text { KEYNOTE-012 } \\
\text { (NCT01848834) }\end{array}$ & $\mathrm{lb}$ & 36 & First-line & $\begin{array}{l}\text { Pembrolizumab } 10 \mathrm{mg} / \mathrm{kg} \text { once every } \\
2 \text { weeks }\end{array}$ & $\begin{array}{l}24 \% \text { vs. } 17 \% \text { (ORR) in PD-L1 positive and } \\
\text { negative, respectively } \\
\text { However, no correlation of PD-L1 } \\
\text { expression with clinical responses to } \\
\text { pembrolizumab }\end{array}$ & {$[11]$} \\
\hline $\begin{array}{l}\text { KEYNOTE-059 } \\
\text { (NCT02335411) }\end{array}$ & II & 133 & Third-line & Pembrolizumab 200 mg Q3W & $\begin{array}{l}22.7 \% \text { vs. } 8.6 \% \text { (ORR) in PD-L1 positive } \\
\text { and negative, respectively }\end{array}$ & {$[16]$} \\
\hline \multicolumn{7}{|l|}{ Nivolumab } \\
\hline $\begin{array}{l}\text { CheckMate-032 } \\
\text { (NCT01928394) }\end{array}$ & $1 / I 1$ & 160 & $\begin{array}{l}\text { Second-line or } \\
\text { later }\end{array}$ & $\begin{array}{l}\text { Nivo } 3 \text { mg/kg Q2W (N3), nivo } 1 \text { mg/ } \\
\text { kg+ipi } 3 \text { mg/kg (N1+l3), or nivo } 3 \text { mg/ } \\
\text { kg+ipi } 1 \text { mg/kg (N3+l1) Q3W×4 cycles, } \\
\text { followed by nivo } 3 \text { mg/kg Q2W }\end{array}$ & $\begin{array}{l}27 \% \text { vs. } 12 \% \text { (ORR), in PD-L1 positive and } \\
\text { negative, respectively }\end{array}$ & {$[10]$} \\
\hline
\end{tabular}

PD-L1, programmed cell death protein ligand 1; ORR, overall response rate. 


\section{ATEZOLIZUMAB (MPDL-3280A)}

A phase I dose-escalation study was conducted to evaluate the pharmacokinetics and safety of atezolizumab. In this trial, atezolizumab monotherapy was administered in patients with non-selected solid tumors, including one GC patient. The ORR was 21\% (NCT01375842).

\section{PD-1/PD-L1 EXPRESSION AND PATIENT OUTCOME}

Melanoma, RCC, and non-small cell lung cancer express high levels of PD-L1, ranging from $66 \%$ to $100 \%$ [19-21]. In a study of $102 \mathrm{GC}$ samples, Wu et al. [22] have demonstrated using an immunohistochemical approach that $42.2 \%$ of the samples had PD-L1 overexpressing tumor cells. They also showed that PD-L1 is undetectable in normal gastric tissue controls and only weakly detectable in gastric adenomas [22]. Similarly, PD-L1 overexpression was found in $40 \%$ of cases of advanced GC from the phase Ib KEYNOTE-012 trial data [11]. Another Chinese study $(n=111)$ reported PD-L1 positivity in $63 \%$ of GC resection specimens [23].

The high PD-L1 expression has been identified as a negative prognostic marker in melanoma [24], RCC [25], and lung cancer [26]. Additionally, PD-L1 upregulation has been detected in gastrointestinal malignancies, such as pancreatic, colorectal, and GC, correlating with poor prognosis [27,28]. Likewise, high PD-L1 expression in GC was associated with nodal metastases, advanced stage, and poor outcome [22,23]. Recently, a small cohort study showed that resected GC patients with a higher CD8+ T-cell density have a higher PD-L1 expression and worse clinical outcome [29]. These biological features in GCs are comparable to those seen in other cancers in which immune checkpoint inhibitors have demonstrated early success. PD-L1 overexpression may also play a role as a predictive response biomarker in GC.

Nevertheless, no biomarker is absolute to predict response to immune checkpoint inhibitors. Hence, an integrated analysis of mutational load, microsatellite instability, needs to be analyzed in responders and non-responders to immune checkpoint inhibitors in GC. The impact of Epstein-Barr Virus status and microsatellite instability status on response to immune checkpoint inhibitors in $\mathrm{GC}$ will be very interesting.

\section{CONCLUSION}

In spite the development of targeted agents such as trastu- zumab and ramucirumab, precision medicine for $\mathrm{GC}$ patients has still a long way to go. Based on the promising early trial results in GC with anti-PD-L1 antibodies such as pembrolizumab, nivolumab, and avelumab, the practice guideline and pattern in metastatic GC patients will be rapidly changed in the next few years. Especially, given the high percentage of MSI-high in GC (up to 20\%), the impact of immunotherapy in these patients will be substantial. With upcoming KEYNOTE 061, KEYNOTE 062 trials, and CheckMate trials, the positioning of immune checkpoint inhibitors in GC will be refined and tuned in the next few years. In addition, identification of responders versus non-responders to immunotherapy will very likely facilitate and improve survival outcome in GC following immunotherapy.

\section{CONFLICTS OF INTEREST}

No potential conflict of interest relevant to this article was reported.

\section{REFERENCES}

1. Ferlay J, Soerjomataram I, Dikshit R, Eser S, Mathers C, Rebelo $\mathrm{M}$, et al. Cancer incidence and mortality worldwide: sources, methods and major patterns in GLOBOCAN 2012. Int J Cancer 2015;136:E359-86.

2. Lee J, Kim KM. Biomarkers for gastric cancer: molecular classification revisited. Precis Future Med 2017;1:59-68.

3. Valsecchi ME. Combined nivolumab and ipilimumab or monotherapy in untreated melanoma. N Engl J Med 2015; 373:1270.

4. Robert C, Schachter J, Long GV, Arance A, Grob JJ, Mortier $L$, et al. Pembrolizumab versus ipilimumab in advanced melanoma. N Engl J Med 2015;372:2521-32.

5. D'Incecco A, Andreozzi M, Ludovini V, Rossi E, Capodanno A, Landi L, et al. PD-1 and PD-L1 expression in molecularly selected non-small-cell lung cancer patients. $\mathrm{Br} \mathrm{J}$ Cancer 2015;112:95-102.

6. Choueiri TK, Figueroa DJ, Fay AP, Signoretti S, Liu Y, Gagnon R, et al. Correlation of PD-L1 tumor expression and treatment outcomes in patients with renal cell carcinoma receiving sunitinib or pazopanib: results from COMPARZ, a randomized controlled trial. Clin Cancer Res 2015;21: 1071-7.

7. Heo JH, Kim HY, Park KC, Hong SJ, Cho KS, Han KS. Expression of programmed cell death ligand $1 / 2$ and BCG immunotherapy in bladder cancer. Cancer Immunol Res 
2015;3(10 Suppl):B41.

8. Ansell SM, Lesokhin AM, Borrello I, Halwani A, Scott EC, Gutierrez M, et al. PD-1 blockade with nivolumab in relapsed or refractory Hodgkin's lymphoma. N Engl J Med 2015;372:311-9.

9. Alexandrov LB, Nik-Zainal S, Wedge DC, Aparicio SA, Behjati S, Biankin AV, et al. Signatures of mutational processes in human cancer. Nature 2013;500:415-21.

10. Janjigian YY, Bendell JC, Calvo E, Kim JW, Ascierto PA, Sharma P. CheckMate-032: Phase I/II, open-label study of safety and activity of nivolumab (nivo) alone or with ipilimumab (ipi) in advanced and metastatic (A/M) gastric cancer (GC) [abstract]. J Clin Oncol 2016;34(15 Suppl):4010.

11. Muro K, Chung HC, Shankaran V, Geva R, Catenacci D, Gupta S, et al. Pembrolizumab for patients with PD-L1 -positive advanced gastric cancer (KEYNOTE-012): a multicentre, open-label, phase $1 \mathrm{~b}$ trial. Lancet Oncol 2016; 17:717-26.

12. Kang YK, Satoh T, Ryu MH, Chao Y, Kato K, Chung HC, et al. Nivolumab (ONO-4538/BMS-936558) as salvage treatment after second or later-line chemotherapy for advanced gastric or gastro-esophageal junction cancer (AGC): a double-blinded, randomized, phase III trial [abstract]. J Clin Oncol 2017;35(4 Suppl):2.

13. Chung HC, Arkenau HT, Wyrwicz L, Oh DY, Lee KW, Infante JR. Avelumab (MSB0010718C; anti-PD-L1) in patients with advanced gastric or gastroesophageal junction cancer from JAVELIN solid tumor phase Ib trial: analysis of safety and clinical activity [abstract]. J Clin Oncol 2016; 34(15 Suppl):4009.

14. Moehler MH, Kim YH, Tan IB, Balogh A, Sanchez TK, Bang YJ. Sequential ipilimumab (Ipi) versus best supportive care (BSC) following first-line chemotherapy (Ctx) in patients (pts) with unresectable locally advanced or metastatic gastric or gastro-esophageal junction (GEJ) cancer: a randomized, open-label, two-arm, phase II trial (CA184162) of immunotherapy as a maintenance concept [abstract]. J Clin Oncol 2013;31(15 Suppl):4151.

15. Ralph C, Elkord E, Burt DJ, O'Dwyer JF, Austin EB, Stern $\mathrm{PL}$, et al. Modulation of lymphocyte regulation for cancer therapy: a phase II trial of tremelimumab in advanced gastric and esophageal adenocarcinoma. Clin Cancer Res 2010;16:1662-72.

16. Fuchs CS, Doi T, Jang RW, Muro K, Satoh T, Machado M. KEYNOTE-059 cohort 1: efficacy and safety of pembrolizumab (pembro) monotherapy in patients with previously treated advanced gastric cancer [abstract]. J Clin Oncol
2017;35(15 Suppl):4003.

17. Segal NH, Hamid O, Hwu W, Massard C, Butler M, Antonia $\mathrm{S}$, et al. 1058PD: a phase I multi-arm dose-expansion study of the anti-programmed cell death-ligand-1 (PDL1) antibody MEDI4736: preliminary data. Ann Oncol 2014;25 Suppl 4:iv365.

18. Chung HC, Arkenau HT, Wyrwicz L, Oh DY, Lee KW, Infante JR, et al. Safety, PD-L1 expression, and clinical activity of avelumab (MSB0010718C), an anti-PD-L1 antibody, in patients with advanced gastric or gastroesophageal junction cancer [abstract]. J Clin Oncol 2016;34(4 Suppl):167.

19. Dong H, Strome SE, Salomao DR, Tamura H, Hirano F, Flies DB, et al. Tumor-associated B7-H1 promotes T-cell apoptosis: a potential mechanism of immune evasion. Nat Med 2002;8:793-800.

20. Konishi J, Yamazaki K, Azuma M, Kinoshita I, Dosaka-Akita $\mathrm{H}$, Nishimura M. B7-H1 expression on non-small cell lung cancer cells and its relationship with tumor-infiltrating lymphocytes and their PD-1 expression. Clin Cancer Res 2004;10:5094-100.

21. Thompson RH, Dong H, Kwon ED. Implications of B7-H1 expression in clear cell carcinoma of the kidney for prognostication and therapy. Clin Cancer Res 2007;13(2 Pt 2): 709s-15s.

22. Wu C, Zhu Y, Jiang J, Zhao J, Zhang XG, Xu N. Immunohistochemical localization of programmed death-1 ligand-1 (PD-L1) in gastric carcinoma and its clinical significance. Acta Histochem 2006;108:19-24.

23. Hou J, Yu Z, Xiang R, Li C, Wang L, Chen S, et al. Correlation between infiltration of FOXP3+ regulatory $T$ cells and expression of $\mathrm{B} 7-\mathrm{H} 1$ in the tumor tissues of gastric cancer. Exp Mol Pathol 2014;96:284-91.

24. Massi D, Brusa D, Merelli B, Ciano M, Audrito V, Serra S, et al. PD-L1 marks a subset of melanomas with a shorter overall survival and distinct genetic and morphological characteristics. Ann Oncol 2014;25:2433-42.

25. Thompson RH, Gillett MD, Cheville JC, Lohse CM, Dong H, Webster WS, et al. Costimulatory $\mathrm{B} 7-\mathrm{H} 1$ in renal cell carcinoma patients: indicator of tumor aggressiveness and potential therapeutic target. Proc Natl Acad Sci U S A 2004;101:17174-9.

26. Mu CY, Huang JA, Chen Y, Chen C, Zhang XG. High expression of PD-L1 in lung cancer may contribute to poor prognosis and tumor cells immune escape through suppressing tumor infiltrating dendritic cells maturation. Med Oncol 2011;28:682-8.

27. Topalian SL, Drake CG, Pardoll DM. Targeting the PD-1/ 
B7-H1(PD-L1) pathway to activate anti-tumor immunity. Curr Opin Immunol 2012;24:207-12.

28. Blank C, Gajewski TF, Mackensen A. Interaction of PD-L1 on tumor cells with PD-1 on tumor-specific T cells as a mechanism of immune evasion: implications for tumor immunotherapy. Cancer Immunol Immunother 2005;54:
307-14.

29. Thompson ED, Zahurak M, Murphy A, Cornish T, Cuka N, Abdelfatah E, et al. Patterns of PD-L1 expression and CD8 $T$ cell infiltration in gastric adenocarcinomas and associated immune stroma. Gut 2017;66:794-801. 